\title{
Students Model in Different Learning Styles of Academic Achievement at the University of Phayao, Thailand
}

\author{
https://doi.org/10.3991/ijet.v14i12.10352 \\ Pratya Nuankaew \\ University of Phayao, Phayao, Thailand \\ Wongpanya Nuankaew $\left({ }^{\varpi}\right)$ \\ wongpanya.nu@rmu.ac.th \\ Kanakarn Phanniphong \\ Rajamangala University of Technology Tawan-Ok, Chon Buri, Thailand \\ Sasithon Imwut \\ Vongchavalitkul University, Nakhon Ratchasima, Thailand \\ Sittichai Bussaman \\ Rajabhat Mahasarakham University, Maha Sarakham, Thailand
}

\begin{abstract}
Attitudes and learning styles can affect academic achievement at different levels. While analyzing attitudes and learning styles can not only use basic statistics, using advanced tools to analyze the students' in-depth elements is discussed. Therefore, this research offers an appropriate method for clustering academic achievement (GPA) that support student's attitudes and learning styles. At the same time, this research is aimed to study the level of attitudes towards learning styles in different academic achievement of students at the University of Phayao. The data collection was conducted from 195 students from 17 schools and colleges at the University of Phayao, Thailand. The results show that there is a variety of cluster in students' attitudes and learning styles with a significant pattern (types of success) of the students' model, while the model performance has a very high efficiency to the model.

In future work, it will be applied with other universities in Thailand and also used in developing applications for providing a program recommended for appropriate educational programs.
\end{abstract}

Keywords-Educational Data Mining, Students Model, Different Academic Achievement, Attitudes Data Mining

\section{Introductions}

In the age of knowledge competition, education is the expectation for the future. Everyone aims for a degree to be used as a competitive tool [1-3, 17-18]. It promotes various processes in improving the quality of education, improving student quality, 
and developing the foundations of an advanced society [3-4]. In addition, it is also used to drive the country and the economy as people with knowledge that can be in competition with other developing or developed nations. The results lead to an education system that plays an important and significant role in all aspects $[4-7,17]$.

For Thailand, education has been developed for a long time. Originally, education in Thailand was conducted in the temples and families. Only men were accepted to undertake an educational learning process. Later, there was a systematic reconstruction of education [10]. Until now, the education system for Thai people is an Education for All [7, 9-10]. Educational management is systematically organized. It has divided the educational level into two stages. The first stage is basic education which begins with an early childhood level, then proceeding into the elementary level, lower secondary level, and finally at the upper secondary level. The secondary stage is higher education, which is an optional final stage of formal learning $[7,10]$.

From the current situation, where technology is changing rapidly, the pattern of learning from the instructor to the lecturer in front of the class is no longer sufficient [1-4]. Searching for learners' perceptions based on the potential and suitability of the learner has received attention from many researchers and educators [7]. Encouraging learners to recognize the process of finding information and knowledge is important [1-2]. These various reasons have convinced the researchers to find the essence of the process. Initially, the researchers found that most of the research was in psychology and educational development, which is often studied in abstract terms and general statistical comparisons [1-4].

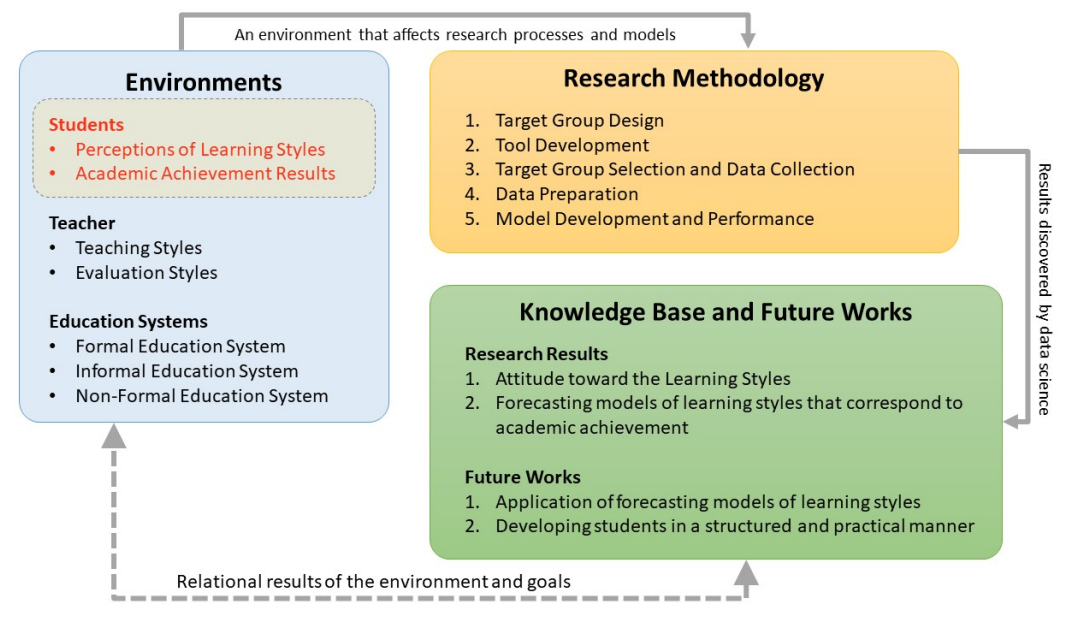

Fig. 1. Research Framework

In this research, the goal of the researchers is clearly different. One is an obvious difference; the researchers want to present some concrete results. The concrete results obtained must be able to measure and evaluate according to the scientific principles. The goal of the research is to conduct in accordance with the research framework shown in Figure 1. From Figure 1, it can be seen that the process and procedures of 
the research has clear goals with clear results. It consists of three components. The first component is the environment which is the cause and importance of research problems. The second component is the research methodology by which researchers describe the operations, results analysis, and performance results. The third component is knowledge bases and future works, which discusses the results and determines future operations.

From the research framework, it emphasizes the importance of research objectives that need to find an appropriate method for clustering academic achievement (GPA) that support student's attitudes and learning styles, which is the beginning of research solutions as shown in Figure 2.

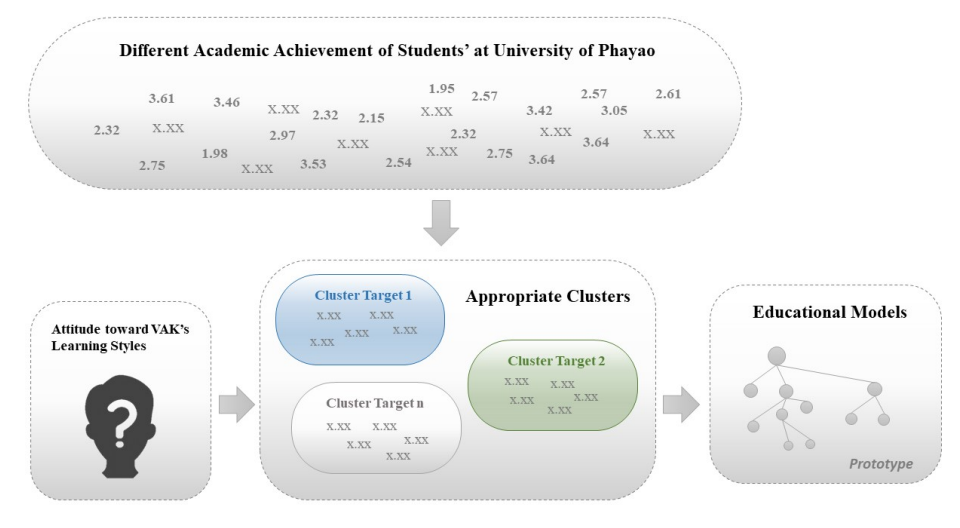

Fig. 2. Research Goals and Research Processes

Picture 2 shows the goal of conducting research. In addition, this research is aimed towards studying the level of attitudes towards learning styles in different academic achievement of students at the University of Phayao. The data collection was conducted from 195 students from 17 schools and colleges at the University of Phayao, Thailand.

The order and outline of the paper are structured in a simple manner which is divided into six sections. The first section discusses the importance and origin of research. The second section summarizes the essentials and other research related to the student's model and academic achievement. The third section describes the process and steps in research methodology. The fourth section is the research report. The fifth section is discussion of the research results. Finally, the sixth section is a summary of all important issues related to the research and future works.

\section{$2 \quad$ Literature and Related Research}

This section is a summary of important and relevant research related to the work of developing students model and analyzing learners' awareness patterns. Topics in this section include student learning styles, and development of educational models. 


\subsection{Student learning styles}

Student learning style refers to the characteristics of student learning behavior [5, $8,11-13,17]$. It is a pattern of learning that responds to individual perceptions: examples are social learning, conceptualization of understanding, and creating interaction with what students want to learn.

Many researchers are trying to study and develop processes that promote perception and create learning patterns that are significant to academic achievement $[9,14-$ 15]. Every research provides many results and benefits to the education system and learners. In addition, the learning styles that have been developed are also varied such as, Kolb's learning styles model which describes the learning style based on the learner's experience [5, 8], Rancourt's learning styles model which describes the learning style based on the learner's psycho-epistemological modes [11], Hemisoheric dominance and learning styles model which describes the learning style based on the learner's hemispheric (brains) preference [11], and VAK's learning styles model which describes the learning style based on the learner's perceptions [11-13]. Each learning style presented earlier is a reference based on the abilities, skills, preferences, and characteristics of each student. However, this research aims to find results that are influenced by the VAK's learning styles.

The VAK's learning style model has been developed by psychologists to identify how students perceive learning. VAK stands for visual (V), auditory (A), and kinesthetic $(\mathrm{K})$, which is the process of getting information for human ways of receiving effective learning and development [12-13]. The specific characteristics of the perception are clearly different. Visual is a characteristic of students who are visually distinctive. They can absorb and retain information better when presented with pictures, diagrams and charts. Auditory is a characteristic of students who have an important role in listening. They will improve their learning in situations of lectures and group discussions. Kinesthetic is a characteristic of learners who like physical movement like physical experiences. They will do better when they act and respond to their activities and learning.

The essence and differences of the VAK's learning styles are shown in Table 1.

Table 1. The essence and differences of the VAK's learning styles

\begin{tabular}{|l|l|l|}
\hline \multicolumn{1}{|c|}{ Visual } & \multicolumn{1}{|c|}{ Auditory } & \multicolumn{1}{c|}{ Kinesthetic } \\
\hline $\begin{array}{l}\text { These learners will respond to } \\
\text { situations such as: } \\
\text { I received a picture. } \\
\begin{array}{l}\text { What do you see? } \\
\text { What are the images in your mind? }\end{array}\end{array}$ & $\begin{array}{l}\text { These learners will respond to } \\
\text { situations such as: } \\
\text { What song makes you feel calm. } \\
\text { The noise caused me to learn } \\
\text { nothing. }\end{array}$ & $\begin{array}{l}\text { These learners will respond to } \\
\text { situations such as: } \\
\text { Body testing makes me feel self- } \\
\text { improvement. } \\
\text { Practice is the heart of the learning } \\
\text { process. }\end{array}$ \\
\hline $\begin{array}{l}\text { Key Points: } \\
\text { Learners respond to picture, graph- } \\
\text { ic, and object }\end{array}$ & $\begin{array}{l}\text { Key Points: } \\
\text { Learners prefer verbal presenta- } \\
\text { tions }\end{array}$ & $\begin{array}{l}\text { Learners prefer a physical, and } \\
\text { hands-on approach }\end{array}$ \\
\hline
\end{tabular}

Table 1 shows the importance and differences of VAK's learning styles which the researchers will apply in the data collection process to analyze the relationship between students' perceptions of academic achievement. 


\subsection{Development of educational models}

The educational model in this research is limited to the prototype of describing the relationship between the learning process, student performance, and student achievement. Therefore, the educational model refers to the scientific process that the researchers focused on to find the facts. This kind of educational model is interesting because the results of that model can be studied further on in a step-by-step manner for application and concrete development of educational quality [5-9, 13].

A clear example of the research of learning styles and further development is the matching of compatible mentor and mentee [5], recommender system of educational programs that match the learner's learning style [7], and using tools to promote learning styles that are relevant to learners $[6,17]$. Moreover, the use of advance technology that is directly related to the analysis of learner behavior can benefit the learners, schools, and the country in a wide range [15]. This tool is called Educational Data Mining (EDM).

Educational Data Mining (EDM) is a new trend of educational reform for the development of students' potential and finding knowledge in a series of overlapping information that focuses on finding useful features and patterns for the performance of the students [15]. Moreover, learning in the 21st century has changed vastly. For example, the role of the teacher changes as an educator who becomes a coach who gives advice. Changes are also in the role of the students who are waiting for knowledge from the instructor to becoming a self-seeking person. Changes in educational facilities in the building or in the classroom become a study from anywhere and anytime through the Internet. Changes in the patterns of teaching and learning of face-to-face is a study through avatars in a virtual classroom. From the example, it can be seen that the educational management model has completely changed [5-9, 13, 15, 18].

Although the educational management model has completely changed the criteria and processes for measuring the results of the students still use the old standard [10]. The assessment criteria still uses the average academic results, which is primarily known as the GPA: Grade Point Average. In Thailand, graduation at primary and secondary levels is determined only with any academic results and completing all activities designated by the school [10]. For the university, only a minimum GPA of 2.00 can be obtained for a bachelor's degree. When considering in-depth study results, it was found that many students graduated inappropriately. In contrast, many schools in Thailand provide high grades to students in order to facilitate learners to gain a competitive advantage in the university entrance examination. It can be seen that using the GPA can only assess the students' performance in general, but not effective in clearly identifying the specific aptitudes of the students. Therefore, this research offers an appropriate method for clustering academic achievement (GPA) that supports the student's attitude and learning styles.

\section{Research Methodology}

The research methodology in this research places great importance on the research process and conceptual framework. It consists of five important parts: 
1. Target group design

2. Tool development

3. Target group selection and data collection

4. Data preparation

5. Model development and performance, as shown in Figure 3.

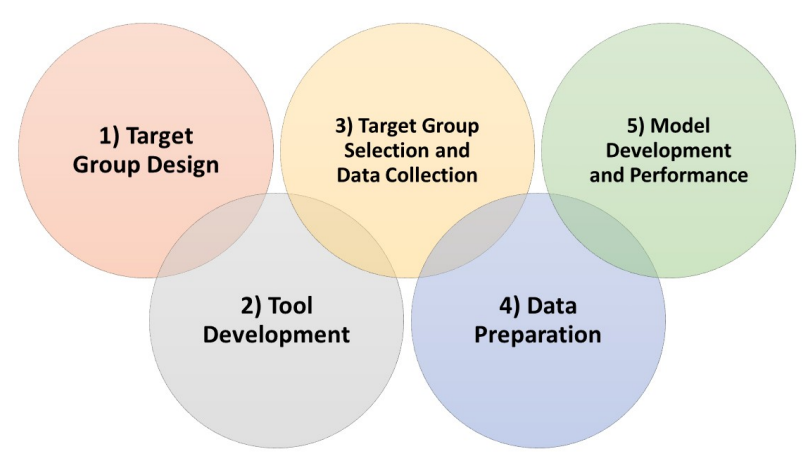

Fig. 3. Research Methodology

\subsection{Target group design}

The target group design aims to be able to share the knowledge towards developing the students' potential and quality of education, which mainly refers to students at the University of Phayao. Thus, the population and sample groups need to be designed in accordance with the overall context of the students at the University of Phayao. The researchers therefore set the goal of collecting data from all schools and colleges at the University of Phayao.

However, the researchers give importance and attention to the research objectives and research questions, which consist of two issues; Question 1: How much does the academic achievement level affect the clusters and learning style of students at the University of Phayao? Question 2: How much of a difference in attitude levels toward the learning style affect the clusters and learning style of students at the University of Phayao?

For finding the answers in this research questions, the researchers used the basic statistical techniques and applied them to the data mining techniques to find the best solutions to the research objectives.

\subsection{Tool development}

The tool used in this research was the questionnaire. It is used to gather attitudes towards various factors. In addition, it is also used to develop the pattern of different learning styles for individual students at the University of Phayao. The questionnaire was in a multiple choice format to make it easier for respondents to provide the in- 
formation. The questionnaire consisted of three sections: Section 1 is the explanation; the objective of section 1 is to explain the purpose of collecting data for this questionnaire. Section 2 is the general information of the respondents; the purpose of section 2 is to summarize the overall replies from the respondents. Section 3 is the level of attitude towards the different learning styles; it is used to analyze various factors related to the learners' attitudes. In addition, the data and information obtained will be used to create and test the models.

After creating the prototype of the questionnaire, the researchers then brought the tool to three experts for consideration to find the efficiency of the questionnaire. The questions used in the questionnaire are in the Thai language, so that respondents were able to obtain a great deal of understanding.

The essence of the questionnaire is shown in Table 2 below.

Table 2. Essence of the Questionnaire

\begin{tabular}{|c|l|c|}
\hline No. & \multicolumn{1}{|c|}{ Questions } & $\begin{array}{c}\text { Perceptions of } \\
\text { Learning Styles }\end{array}$ \\
\hline 1. & Students can learn better by reading the books. & Visual \\
\hline 2. & When students try to do things by themselves, they can do better. & Kinesthetic \\
\hline 3. & Students can remember what they hear in class, better than what they read. & Auditory \\
\hline 4. & When students have read, the students can understand the lesson better. & Visual \\
\hline 5. & Students learn better when listening in class. & Auditory \\
\hline 6. & Students understand what they learn better when they have a role or action. & Kinesthetic \\
\hline 7. & $\begin{array}{l}\text { Students will learn better when hearing from other friends, and talking about } \\
\text { the subjects learned in class. }\end{array}$ & Auditory \\
\hline 8. & Students learn better from reading rather than listening or hearing. & Visual \\
\hline 9. & If students have participated in class activities, students will learn better. & Kinesthetic \\
\hline
\end{tabular}

Table 2 shows the details of the questions in section 3, which consists of 9 questions. In addition, Table 2 also shows the types of perceptions and learning styles of each questions. In rating the attitude level to the question, the researchers used the Likert's scale method, which consists of five levels. Setting the score and meaning of acceptance are displayed in Table 3:

Table 3. Score and Meaning

\begin{tabular}{|c|c|}
\hline Score & Meaning \\
\hline 1 & Strongly disagree \\
\hline 2 & Disagree \\
\hline 3 & Neither agree nor disagree \\
\hline 4 & Agree \\
\hline 5 & Strongly agree \\
\hline
\end{tabular}

\subsection{Target group selection and data collection}

In selecting the sample group, the researchers determined that it would be more comprehensive by requiring the sample group from all departments at the University of Phayao. The departments obtained from the University of Phayao consisted of 17 
schools and colleges; College of Continuing Education, School of Agriculture and Natural Resources, School of Allied Health Sciences, School of Architecture and Fine Arts, School of Dentistry, School of Energy and Environment, School of Engineering, School of Information and Communication Technology, School of Law, School of Liberal Arts, School of Management and Information Sciences, School of Medical Sciences, School of Medicine, School of Nursing, School of Pharmaceutical Sciences, School of Political and Social Science, and School of Science.

Upon collecting data in the research from the students in the University of Phayao, the students who were studying in the academic year 2018 had been randomly selected.

\subsection{Data preparation}

The process of preparing data is the most time-consuming step. The best model can be obtained from a good data mining analysis, which needs to be prepared for data availability and accuracy. Therefore, the preparation of data for use in the analysis must be given special importance.

Data preparation consists of three sub-steps: data selection, data cleaning, and data transformation. Data selection is the information used to determine the goals and objectives of the analysis and used to select only relevant information. Data cleaning is the process of filtering data by removing redundant data and correcting data that is faulty. Data transformation is the process of converting the data format into the correct format and allowing the data to be used for analysis according to the process of data mining.

\subsection{Model development and performance}

Model development and performance are the processes of analyzing and designing a process for developing and testing a model which consists of four main steps:

1. Clustering analysis

2. Determining the number of clusters

3. Implementing model

4. Model performance

Clustering analysis: Clustering analysis is the analysis process for grouping the density to balance the data in data collection. The data used in grouping is the grade point average of students (GPA). It is used to separate student's performance that refers to the academic achievement of a set of related data collection.

Tools used for analyzing cluster are k-Means and x-Means, where k-Means is used to determine the number of the optimal members in each data sets. For example, the minimum of GPA in data set is equal to 1.90 , the maximum of GPA in data set is equal to 3.90, and the average of GPA in data set is equal to 2.97. The median of GPA in data set is equal to 2.90. It can be seen that the average of GPA is over than the median of GPA, which used k-Means to re-group the appropriate cluster in each data 
series. X-Means clustering is the change management of k-Means clustering, which manages cluster allocations by trying to replicate partitions and separates the best results until a certain threshold is reached. The goal is determining the intrinsic group in a set of unlabeled data.

Determining the Number of Clusters: Determining the number of clusters is how to select the appropriate clusters. The method chosen to decide the number of clusters was called k-optimization [5]. K-Optimization is based on an elbow decision concept for selecting $\mathrm{k}$-value and $\mathrm{x}$-values. The decision of selecting $\mathrm{k}$-value and $\mathrm{x}$-values is selecting the value where $\mathrm{k}$ and $\mathrm{x}$ have an urgent change. For example, the vertical change is markedly horizontal, which is shown in Figure 4.

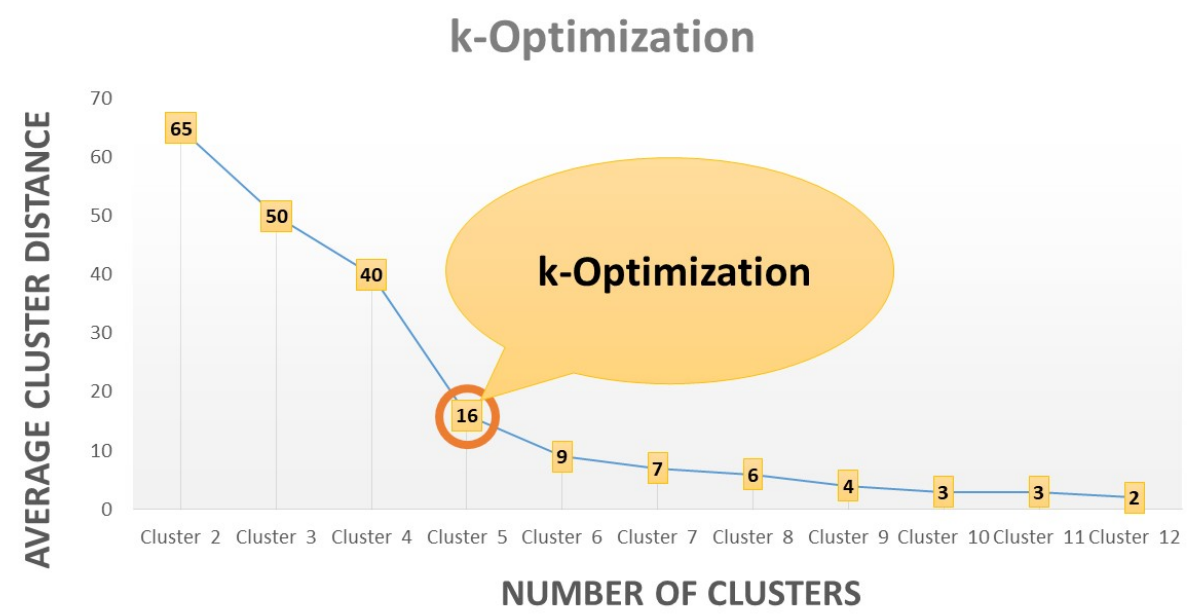

Fig. 4. Determining the Number of Clusters

Implementing Model: Implementing model is the process of developing models from data sets. The tools used to create models are decision trees and association rules. Decision tree is a data mining technique that is used to find the significant attributes by applying attribute selection from the node in the decision tree model [7-8]. In addition, the decision tree develops the effectiveness of the clustering by applying the decision tree to be tested in each clusters. The association rules is a data mining technique that converts the decision tree model into a process to forecast future data sets.

Model Performance: Model performance is the process of finding the model's performance. It consists of two parts: data testing methods and model selection methods. Data testing methods use the cross-validation methods to evaluate model by separating the data collected into two sets that include a training dataset and testing dataset. Training dataset is used for building the model. The testing dataset is used for testing the model. The cross-validation methods in this paper are two types including k-fold cross-validation and leave-one-out cross-validation, as shown in Figure 5. 


\section{Set of the Data}

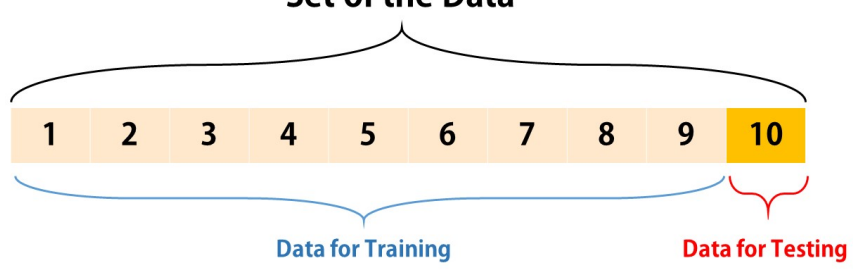

Fig. 5. Cross-Validation Method

Model selection methods are considered to be based on an overview of the model results, which is reasonable considering the validity, effectiveness, model pattern, and applicability. The criteria of consideration are accuracy, precision, and recall [8].

Accuracy is the ability to choose the outcome of predictions, which is calculated from Equation (1), as from the confusion matrix [8] shown in Table 4. While, precision is a part of the prediction, which involves the retrieve instances. Finally, recall is the fraction of relevant instances that are retrieved.

$$
\text { Accuracy }=\frac{T P+T N}{T P+F P+F N+T N}
$$

Table 4. Confusion Matrix

\begin{tabular}{|l|l|l|l|}
\hline \multirow{2}{*}{ Predicted / Actual } & \multicolumn{1}{c|}{ True Condition } & \multirow{2}{*}{ Precision } \\
\cline { 2 - 3 } & \multicolumn{1}{|c|}{ Positive } & \multicolumn{1}{c|}{ Negative } & \\
\hline Predicted Positive & True Positive (TP) & False Positive (FP) & Precision (Positive) $=\frac{\boldsymbol{T P}}{\boldsymbol{T P}+\boldsymbol{F P}}$ \\
\hline Predicted Negative & False Negative (FN) & True Negative (TN) & Precision (Negative) $\frac{\boldsymbol{T P}}{\boldsymbol{T P}+\boldsymbol{F P}}$ \\
\hline Recall & Recall (Positive) $=\frac{\boldsymbol{T P}}{\boldsymbol{T P}+\boldsymbol{F N}}$ & Recall (Negative) $=\frac{\boldsymbol{T N}}{\boldsymbol{F P}+\boldsymbol{T N}}$ & \\
\hline
\end{tabular}

\section{$4 \quad$ Research Results}

The objective of the research results section is to report the performance related to this research, which consists of five issues:

1. Number of respondents

2. Attitudes towards perceived factors and learning styles

3. Appropriate cluster analysis results

4. Model development results

5. Model testing results discussions. 


\subsection{Number of respondents}

In this section, the survey report is summarized and the questionnaire has been answered. The researchers collected data from 195 questionnaires from the sample group of students who were studying at the University of Phayao. From the sample group, the analysis results are divided into two parts as follows: Table 5 shows the general information of respondents, and Table 6 shows the number and percentage of respondents classified by the schools and colleges.

Table 5. General Information of Respondents

\begin{tabular}{|l|l|l|c|c|c|c|}
\hline \multirow{2}{*}{ Gender } & \multirow{2}{*}{ Respondents } & \multicolumn{5}{|c|}{ Academic Year } \\
\cline { 3 - 7 } & & $\boldsymbol{1}^{\text {st }}$ Year & $2^{\text {nd }}$ Year & $3^{\text {rd }}$ Year & $4^{\text {th }}$ Year & $\mathbf{5}^{\text {th }}$ Year \\
\hline Male & $70(35.90 \%)$ & $8(33.33 \%)$ & $30(56.60 \%)$ & $31(35.23 \%)$ & $7(30.43 \%)$ & $1(14.29 \%)$ \\
\hline Female & $125(64.10 \%)$ & $16(66.67 \%)$ & $23(43.40 \%)$ & $57(64.77 \%)$ & $16(69.57 \%)$ & $6(85.71 \%)$ \\
\hline Total & $195(100 \%)$ & $24(12.31 \%)$ & $53(27.18 \%)$ & $88(45.13 \%)$ & $23(11.79 \%)$ & $7(3.59 \%)$ \\
\hline
\end{tabular}

Table 5 shows that most respondents are female, which is equal to 125 (64.10\%) respondents. While $70(35.90 \%)$ male responded to the questionnaire. In addition, most respondents are studying in the third year with $88(45.13 \%)$ respondents. While the year that provides the least questionnaire is the fifth year, which has $7(3.59 \%)$ respondents.

Table 6. Number and Percentage of Respondents Classified by Schools and Colleges

\begin{tabular}{|l|c|c|}
\hline \multicolumn{1}{|c|}{ Schools and Colleges } & Respondents & Percentage \\
\hline College of Continuing Education & 28 & $14.36 \%$ \\
\hline School of Agriculture and Natural Resources & 6 & $3.08 \%$ \\
\hline School of Allied Health Sciences & 6 & $3.08 \%$ \\
\hline School of Architecture and Fine Arts & 6 & $3.08 \%$ \\
\hline School of Dentistry* & 1 & $0.51 \%$ \\
\hline School of Energy and Environment & 2 & $1.03 \%$ \\
\hline School of Engineering & 12 & $6.15 \%$ \\
\hline School of Information and Communication Technology & 19 & $9.74 \%$ \\
\hline School of Law & 12 & $6.15 \%$ \\
\hline School of Liberal Arts & 10 & $5.13 \%$ \\
\hline School of Management and Information Sciences & 29 & $14.87 \%$ \\
\hline School of Medical Sciences & 12 & $6.15 \%$ \\
\hline School of Medicine* & 35 & $17.95 \%$ \\
\hline School of Nursing & 2 & $1.03 \%$ \\
\hline School of Pharmaceutical Sciences & 7 & $3.59 \%$ \\
\hline School of Political and Social Science & 5 & $2.56 \%$ \\
\hline School of Science & 3 & $1.54 \%$ \\
\hline Total & 195 & $100 \%$ \\
\hline
\end{tabular}

Table 6 shows that the respondents were classified by schools and colleges. It displays that most respondents are in the School of Medicine with 35 (17.95\%) respondents. The second school that provided information is the School of Management and 
Information Sciences with 29 (14.87\%) respondents. The third school that provided information is the College of Continuing Education with 28 (14.36\%) respondents. While the school that provided the least information is the School of Dentistry with 1 $(0.51 \%)$ respondents.

\subsection{Attitudes towards perceived factors and learning styles}

This section summarizes the results of the attitude towards 9 questions using statistical techniques including average (means), standard deviation (S.D.) and interpretation as shown in Table 7.

In the interpretation of the data, the researchers divided the distance of each class according to the rating level. The calculation process and result used the maximum score (equal to 5) minus the minimum score (equal to 1 ) divided by the number of class (equal to 5), as shown in equation (2).

$$
\begin{aligned}
\text { Width of the class } & =\frac{\text { Maximum score }- \text { Minimum score }}{\text { Number of class }} \\
& =\frac{5-1}{5} \\
& =0.8
\end{aligned}
$$

From the result of the calculation in equation 2 , the result is equal to 0.8 . Thus, it can be used to define the rating criteria for use in the interpretation of the level of attitude on each question as shown in Table 7.

Table 7. Class, Width of the class, and Interpretation

\begin{tabular}{|c|l|c|}
\hline Class & \multicolumn{1}{|c|}{ Width of the class } & Interpretation \\
\hline 1 & In the range between $1.00-1.80$ & Strongly disagree \\
\hline 2 & In the range between $1.81-2.60$ & Disagree \\
\hline 3 & In the range between $2.61-3.40$ & Neither agree nor disagree \\
\hline 4 & In the range between $3.41-4.20$ & Agree \\
\hline 5 & In the range between $4.21-5.00$ & Strongly agree \\
\hline
\end{tabular}

Table 8. Attitudes towards Perceived Factors and Learning Styles

\begin{tabular}{|c|l|c|c|l|}
\hline Question No. & \multicolumn{1}{|c|}{ Learning Styles } & Means & S.D. & \multicolumn{1}{|c|}{ Interpretation } \\
\hline Q1 & Visual & 3.75 & 0.84 & Agree \\
\hline Q2* & Kinesthetic & 4.02 & 0.83 & Agree \\
\hline Q3 & Auditory & 3.75 & 0.81 & Agree \\
\hline Q4 & Visual & 3.83 & 0.89 & Agree \\
\hline Q5 & Auditory & 3.72 & 0.87 & Agree \\
\hline Q6 & Kinesthetic & 3.66 & 0.93 & Agree \\
\hline Q7* & Auditory & 3.65 & 0.89 & Agree \\
\hline Q8 & Visual & 3.69 & 0.94 & Agree \\
\hline Q9 & Kinesthetic & 3.83 & 0.83 & Agree \\
\hline \multicolumn{2}{r}{ Summaries } & 3.77 & 0.87 & Agree \\
\hline
\end{tabular}


Table 8 shows that students at the University of Phayao gave opinions on the attitude level towards learning styles in same interpretations. From the survey, it was found that the respondents expressed their opinions on the most important learning styles of kinesthetic, which shows the average in question 2 (Mean $=4.02)$. On the other hand, respondents pay less attention to auditory, which shows the average value in question 7 (Mean $=3.65)$. However, the relationship of learning styles in different academic achievement of the students at the University of Phayao can be expressed in 6 patterns and summarizes the group of respondents by patterns as shown in Table 9 .

Table 9. Learning Styles in Different Academic Achievement of Students

\begin{tabular}{|c|c|c|}
\hline Patterns & Number of Students & Percentages \\
\hline Pattern 1: Auditory - Kinesthetic - Visual (A-K-V) & \begin{tabular}{|l|r|}
39 \\
\end{tabular} & $20.00 \%$ \\
\hline Pattern 2: Auditory - Visual - Kinesthetic (A-V-K) & 20 & $10.26 \%$ \\
\hline Pattern 3: Kinesthetic - Auditory - Visual (K-A-V) & 28 & $14.36 \%$ \\
\hline Pattern 4: Kinesthetic - Visual - Auditory (K-V-A) & 39 & $20.00 \%$ \\
\hline Pattern 5: Visual - Auditory - Kinesthetic (V-A-K) & 29 & $14.87 \%$ \\
\hline Pattern 6: Visual - Kinesthetic - Auditory (V-K-A) & 40 & $20.51 \%$ \\
\hline Total: & 195 & $100 \%$ \\
\hline
\end{tabular}

Identifying students in each patterns were based on the calculation results from each attitude level of the question. For example, the respondents rated the attitude towards each question as follows: Q1 $=3, \mathrm{Q} 2=5, \mathrm{Q} 3=3, \mathrm{Q} 4=4, \mathrm{Q} 5=3, \mathrm{Q} 6=4$, $\mathrm{Q} 7=3, \mathrm{Q} 8=3$, and $\mathrm{Q} 9=4$. The calculation is for using the total score of the attitude level towards the learning style in which each question is based on the perception of learning styles as follows: Visual learning style has Q1, Q4, and Q8. Auditory learning style has Q3, Q5, and Q7. Kinesthetic learning style has Q2, Q6, and Q9. So the result from the sample is equal to the visual learning style $=10$, auditory learning style $=9$, and kinesthetic learning style $=13$. When sorting the score, it can be concluded that this respondent is in Pattern $4(\mathrm{~K}-\mathrm{V}-\mathrm{A})$.

\subsection{Appropriate cluster analysis results}

This section is the result of analyzing the appropriate number of clusters to be used to develop predictive models that are consistent with the academic achievement of future learners. The data used in the analysis are grade point average (GPA). After obtaining the appropriate number of clusters, it will be referenced to the level of attitude towards the different learning styles to create a decision tree model.

There are two optimal value results from determining the number of clusters process; k-Optimization for k-Means, and $\mathrm{x}$-Means clustering summary from k-Optimization as shown in Figure 6 and Figure 7.

Figure 6 shows that k-Optimization of k-Means is equal to 5 . From all groups, the $\mathrm{k}$ values selected vertically and horizontally change in the elbow decision concept. The $\mathrm{k}$ values are determined by the vertical and horizontal sudden changes.

Figure 7 shows that k-Optimization of $x$-Means is equal to 5 . When considering Figure 6 and Figure 7, it is very consistent to select a cluster that is number 5 for k- 
value. Therefore, when considered thoroughly, it is appropriate to use $\mathrm{k}=5$ which will be used in the development of the model. In addition, Table 10 shows the number of members and the average distance between clusters.

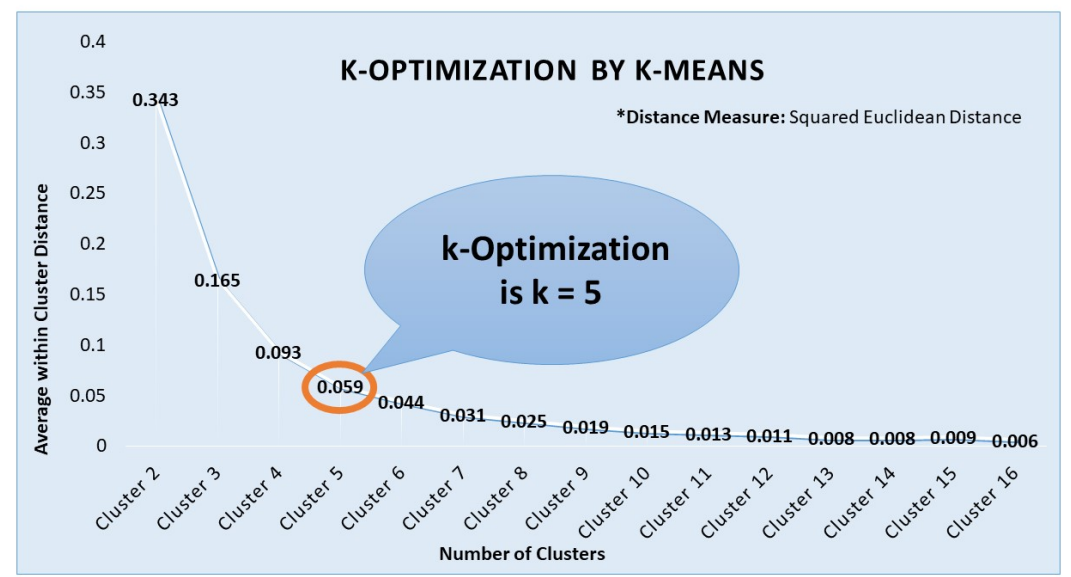

Fig. 6. k-Optimization of k-Means

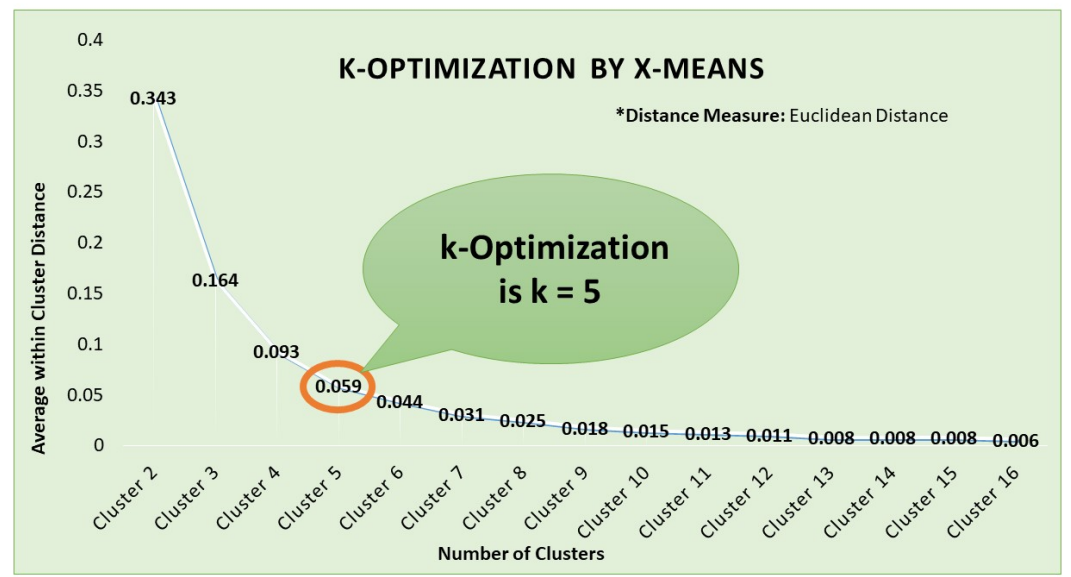

Fig. 7. k-Optimization of $x-$ Means

Table 10. Members, Average within Cluster Distance, and Average within Centroid

\begin{tabular}{|l|l|c|c|}
\hline \multicolumn{1}{|c|}{ Cluster } & \multicolumn{1}{c|}{ Member } & $\begin{array}{c}\text { Average within Cluster } \\
\text { Distance }\end{array}$ & Average within Centroid \\
\hline Cluster_0 & $37(18.97 \%)$ & 0.104 & 3.59 \\
\hline Cluster_1 & $47(24.10 \%)$ & 0.036 & 3.18 \\
\hline Cluster_2* & $59(30.26 \%)$ & 0.045 & 2.87 \\
\hline Cluster_3 & $40(20.51 \%)$ & 0.052 & 2.53 \\
\hline Cluster_4 & $12(6.15 \%)$ & 0.099 & 2.13 \\
\hline Total: & $195(100 \%)$ & 0.059 & 2.86 \\
\hline
\end{tabular}




\subsection{Model development results}

After knowing the optimal number of clusters, this step is to report the analysis of attitude patterns to the difference in academic achievement by analyzing each cluster. From the appropriate cluster, the cluster can be divided according to the grade point average (GPA) of the respondents as shown in Table 11.

Table 11. Clusters, Grade Point Average (GPA), and Priorities Perceptions of Learning Styles

\begin{tabular}{|l|l|l|l|l|l|}
\hline \multirow{2}{*}{ Cluster } & \multicolumn{2}{|c|}{ GPA } & \multirow{2}{*}{ Member } & \multicolumn{2}{c|}{ Priorities Perceptions of Learning Styles } \\
\cline { 5 - 6 } & & & \multicolumn{1}{c|}{ Visual } & \multicolumn{1}{c|}{ Auditory } & \multicolumn{1}{c|}{ Kinesthetic } \\
\hline Cluster_0 & $3.41-3.90$ & $37(18.97 \%)$ & $15(7.69 \%)$ & $12(6.15 \%)$ & $10(5.13 \%)$ \\
\hline Cluster_1 & $3.03-3.33$ & $47(24.10 \%)$ & $14(7.18 \%)$ & $14(7.18 \%)$ & $19(9.74 \%)$ \\
\hline Cluster_2* & $2.71-3.02$ & $59(30.26 \%)$ & $23(11.79 \%)$ & $15(7.69 \%)$ & $21(10.77 \%)$ \\
\hline Cluster_3 & $2.34-2.70$ & $40(20.51 \%)$ & $11(5.64 \%)$ & $13(6.67 \%)$ & $16(8.21 \%)$ \\
\hline Cluster_4 & $1.90-2.31$ & $12(6.15 \%)$ & $6(3.08 \%)$ & $5(2.56 \%)$ & $1(0.51 \%)$ \\
\hline Total: & & $195(100 \%)$ & $69(35.38 \%)$ & $59(30.26 \%)$ & $67(34.36 \%)$ \\
\hline
\end{tabular}

*Maximum GPA $=3.90$, Minimum GPA $=1.90$

Table 11 shows members in each cluster based on the respondent's data and priorities perceptions of learning styles. It showed that the cluster with the most members is Cluster_2 which has $59(30.26 \%)$ members. The second is Cluster_1 with 47 $(24.10 \%)$ members. The third is Cluster_3 with $40(20.51 \%)$ members. The fourth is Cluster_0 with $37(18.97 \%)$ members. Finally, the last is Cluster_4 with 12 (6.15\%) members.

After that, the researchers separated each set of data and analyzed the numbers by the decision tree and cross-validation techniques. The results of the analysis of the decision tree's performance is shown in Table 12 to Table 21.

Decision Tree's Performance of Cluster_0. Table 12 shows that the model that is efficient and suitable for Cluster_0 is the decision tree model at depth 5 and used the Leave-one-out cross-validation method. After knowing the effective model of Cluster_0, Table 13 shows the results of the Cluster_0 model testing.

Table 12. Decision Tree's Performance of Cluster_0

\begin{tabular}{|l|c|c|c|}
\hline \multirow{2}{*}{ Depth of Model / Accuracy } & \multicolumn{3}{|c|}{ Cross Validation } \\
\cline { 2 - 4 } & $\mathbf{5 - F o l d}$ & $\mathbf{1 0 - F o l d}$ & Leave-one-out \\
\hline Depth 3 & $45.71 \%$ & $35.83 \%$ & $59.46 \%$ \\
\hline Depth 5* & $43.21 \%$ & $48.33 \%$ & $67.57 \% *$ \\
\hline Depth 7 & $43.21 \%$ & $48.33 \%$ & $67.57 \%$ \\
\hline
\end{tabular}

Table 13.

Cluster_0 Model Testing

\begin{tabular}{|l|c|c|c|c|}
\hline \multirow{2}{*}{ Predicted / Actual } & \multicolumn{3}{|c|}{ True Condition } & \multirow{2}{*}{ Precision } \\
\cline { 2 - 5 } & Kinesthetic & Visual & Auditory & \\
\hline Pred. Kinesthetic & 9 & 4 & 5 & $50.00 \%$ \\
\hline Pred. Visual & 1 & 10 & 1 & $83.33 \%$ \\
\hline Pred. Auditory & 0 & 1 & 6 & $85.71 \%$ \\
\hline Recall & $90.00 \%$ & $66.67 \%$ & $50.00 \%$ & \\
\hline
\end{tabular}


Decision Tree's Performance of Cluster_1. Table 14 shows that the model that is efficient and suitable for Cluster_1 is the decision tree model at depth 3 and used the 10-Fold cross-validation method. While, Table 15 shows the results of the Cluster_1 model testing.

Table 14. Decision Tree's Performance of Cluster_1

\begin{tabular}{|l|c|c|c|}
\hline \multirow{2}{*}{ Depth of Model / Accuracy } & \multicolumn{3}{|c|}{ Cross Validation } \\
\cline { 2 - 4 } & $\mathbf{5 - F o l d}$ & $\mathbf{1 0 - F o l d}$ & Leave-one-out \\
\hline Depth 3* & $46.89 \%$ & $47.50 \% *$ & $34.04 \%$ \\
\hline Depth 5 & $46.89 \%$ & $43.00 \%$ & $34.04 \%$ \\
\hline Depth 7 & $46.89 \%$ & $43.00 \%$ & $34.04 \%$ \\
\hline
\end{tabular}

Table 15.

Cluster_1 Model Testing

\begin{tabular}{|l|c|c|c|c|}
\hline \multirow{2}{*}{ Predicted / Actual } & \multicolumn{3}{|c|}{ True Condition } & \multirow{2}{*}{ Precision } \\
\cline { 2 - 5 } & Kinesthetic & Visual & Auditory & \\
\hline Pred. Kinesthetic & 16 & 6 & 5 & $59.26 \%$ \\
\hline Pred. Visual & 3 & 6 & 9 & $33.33 \%$ \\
\hline Pred. Auditory & 0 & 2 & 0 & $0.00 \%$ \\
\hline Recall & $84.21 \%$ & $42.86 \%$ & $0.00 \%$ & \\
\hline
\end{tabular}

Decision Tree's Performance of Cluster_2. Table 16 shows that the model that is efficient and suitable for Cluster_2 is the decision tree model at depth 5 and used the 5-Fold cross-validation method. While, Table 17 shows the results of the Cluster_2 model testing.

Table 16. Decision Tree's Performance of Cluster_2

\begin{tabular}{|l|l|l|l|}
\hline \multirow{2}{*}{ Depth of Model / Accuracy } & \multicolumn{3}{|c|}{ Cross Validation } \\
\cline { 2 - 4 } & \multicolumn{1}{|c|}{ 5-Fold } & \multicolumn{1}{c|}{ 10-Fold } & Leave-one-out \\
\hline Depth 3 & $52.73 \%$ & $41.67 \%$ & $50.85 \%$ \\
\hline Depth 5* & $56.06 \% *$ & $53.33 \%$ & $50.85 \%$ \\
\hline Depth 7 & $56.06 \%$ & $53.33 \%$ & $50.85 \%$ \\
\hline
\end{tabular}

Table 17. Cluster_2 Model Testing

\begin{tabular}{|l|c|c|c|c|}
\hline \multirow{2}{*}{ Predicted / Actual } & \multicolumn{3}{|c|}{ True Condition } & \multirow{2}{*}{ Precision } \\
\cline { 2 - 4 } & Kinesthetic & Visual & Auditory & \\
\hline Pred. Kinesthetic & 3 & 2 & 2 & $42.86 \%$ \\
\hline Pred. Visual & 5 & 12 & 3 & $60.00 \%$ \\
\hline Pred. Auditory & 7 & 7 & 18 & $56.25 \%$ \\
\hline Recall & $20.00 \%$ & $57.14 \%$ & $78.26 \%$ & \\
\hline
\end{tabular}

Decision Tree's Performance of Cluster_3. Table 18 shows that the model that is efficient and suitable for Cluster_3 is the decision tree model at depth 3 and used the 5-Fold cross-validation method. While, Table 19 shows the results of the Cluster_3 model testing. 
Paper-Students Model in Different Learning Styles of Academic Achievement at the University of ..

Table 18. Decision Tree's Performance of Cluster 3

\begin{tabular}{|l|c|c|c|}
\hline \multirow{2}{*}{ Depth of Model / Accuracy } & \multicolumn{3}{|c|}{ Cross Validation } \\
\cline { 2 - 4 } & 5-Fold & 10-Fold & Leave-one-out \\
\hline Depth 3* & $47.50 \% *$ & $40.00 \%$ & $45.00 \%$ \\
\hline Depth 5 & $47.50 \%$ & $42.50 \%$ & $47.50 \%$ \\
\hline Depth 7 & $47.50 \%$ & $42.50 \%$ & $47.50 \%$ \\
\hline
\end{tabular}

Table 19.

Cluster_3 Model Testing

\begin{tabular}{|l|c|c|c|c|}
\hline \multirow{2}{*}{ Predicted / Actual } & \multicolumn{3}{|c|}{ True Condition } & \multirow{2}{*}{ Precision } \\
\cline { 2 - 5 } & Kinesthetic & Visual & Auditory & \\
\hline Pred. Kinesthetic & 6 & 5 & 2 & $46.15 \%$ \\
\hline Pred. Visual & 4 & 7 & 3 & $50.00 \%$ \\
\hline Pred. Auditory & 6 & 1 & 6 & $46.15 \%$ \\
\hline Recall & $37.50 \%$ & $53.85 \%$ & $54.55 \%$ & \\
\hline
\end{tabular}

Decision Tree's Performance of Cluster_4. Table 20 shows that the model that is efficient and suitable for Cluster_ 4 is the decision tree model at depth 3 and used the 5_Fold cross-validation method. While, Table 21 shows the results of the Cluster_4 model testing.

Table 20.

Decision Tree's Performance of Cluster_4

\begin{tabular}{|l|c|c|c|}
\hline \multirow{2}{*}{ Depth of Model / Accuracy } & \multicolumn{3}{|c|}{ Cross Validation } \\
\cline { 2 - 4 } & $\mathbf{5 - F o l d}$ & $\mathbf{1 0 - F o l d}$ & Leave-one-out \\
\hline Depth 3* & $40.00 \% *^{*}$ & $30.00 \%$ & $33.33 \%$ \\
\hline Depth 5 & $40.00 \%$ & $30.00 \%$ & $33.33 \%$ \\
\hline Depth 7 & $40.00 \%$ & $30.00 \%$ & $33.33 \%$ \\
\hline
\end{tabular}

Table 21.

Cluster_4 Model Testing

\begin{tabular}{|l|c|c|c|c|}
\hline \multirow{2}{*}{ Predicted / Actual } & \multicolumn{3}{|c|}{ True Condition } & \multirow{2}{*}{ Precision } \\
\cline { 2 - 5 } & Kinesthetic & Visual & Auditory & \\
\hline Pred. Kinesthetic & 5 & 5 & 1 & $45.45 \%$ \\
\hline Pred. Visual & 1 & 0 & 0 & $0.00 \%$ \\
\hline Pred. Auditory & 0 & 0 & 0 & $0.00 \%$ \\
\hline Recall & $83.33 \%$ & $0.00 \%$ & $0.00 \%$ & \\
\hline
\end{tabular}

\subsection{Model Testing Results Discussions}

In this section, the researchers wanted to present and discuss the results of the model testing in each cluster. From Table 12 to Table 21, the result shows that the models in each cluster have a distinct relationship. As a result of this model testing, the researchers showed the model in each cluster in Figure 8 to Figure 12. 


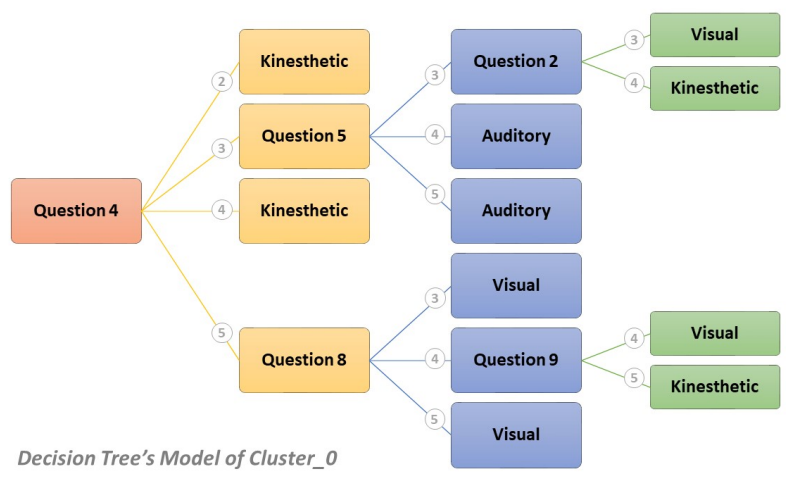

Fig. 8. Decision Tree's Model of Cluster_0

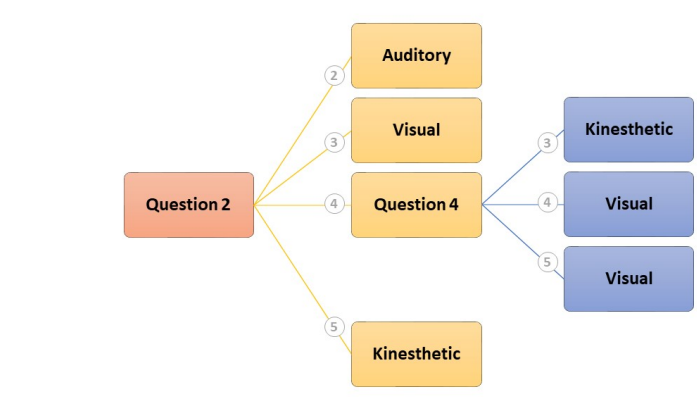

Decision Tree's Model of Cluster_1

Fig. 9. Decision Tree's Model of Cluster_1

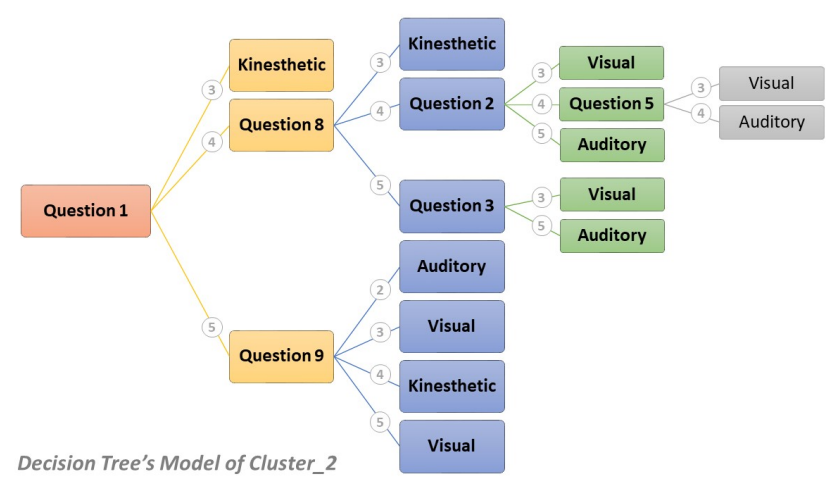

Fig. 10.Decision Tree's Model of Cluster_2 


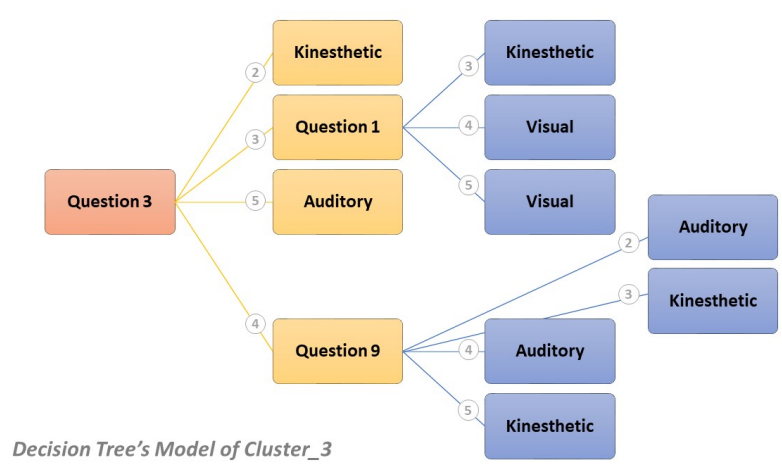

Fig. 11.Decision Tree's Model of Cluster_3

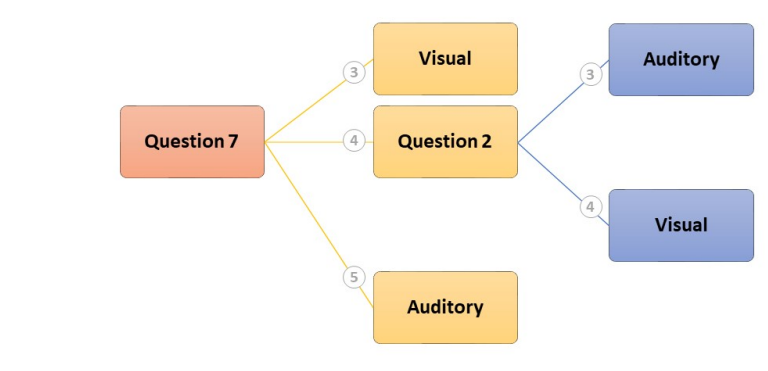

Decision Tree's Model of Cluster_4

Fig. 12.Decision Tree's Model of Cluster_4

Figure 8 to Figure 12 show all models that have relationships in each cluster, which is an overview of the prediction model analysis shown in Table 22, Table 23 and Figure 13.

Table 22. Decision Tree's Performance with Data Collection

\begin{tabular}{|l|c|c|c|}
\hline \multirow{2}{*}{ Depth of Model / Accuracy } & \multicolumn{3}{|c|}{ Cross Validation } \\
\cline { 2 - 4 } & 5-Fold & 10-Fold & Leave-one-out \\
\hline Depth 3 & $60.51 \%$ & $56.92 \%$ & $58.46 \%$ \\
\hline Depth 5 & $72.31 \%$ & $72.79 \%$ & $69.74 \%$ \\
\hline Depth 7* & $72.82 \%$ & $74.32 \% *$ & $71.28 \%$ \\
\hline
\end{tabular}

Table 22 shows that the model that is efficient and suitable for data collection is the decision tree model at depth 7 and used the 10-Fold cross-validation method. After knowing the effective model for data collection, Table 23 shows the results of the decision tree's performance and decision tree model as shown in Figure 13. 
Table 23.

Cluster_3 Model Testing

\begin{tabular}{|l|c|c|c|c|}
\hline \multirow{2}{*}{ Predicted / Actual } & \multicolumn{3}{|c|}{ True Condition } & \multirow{2}{*}{ Precision } \\
\cline { 2 - 5 } & Kinesthetic & Visual & Auditory & $75.31 \%$ \\
\hline Pred. Kinesthetic & 61 & 7 & 13 & $70.49 \%$ \\
\hline Pred. Visual & 3 & 43 & 15 & $77.36 \%$ \\
\hline Pred. Auditory & 3 & 9 & 41 & \\
\hline Recall & $91.04 \%$ & $72.88 \%$ & $59.42 \%$ & \\
\hline
\end{tabular}

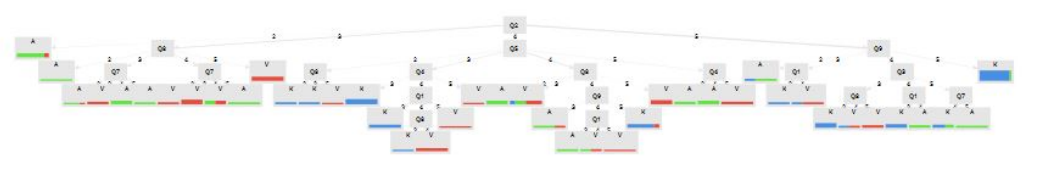

Fig. 13.Decision Tree's Model

Figure 13 shows the prediction model with the decision tree mode that has a relationship between different learning styles of student achievement at the University of Phayao, Thailand. In addition, this decision tree model can be applied in association rules as shown in Table 24 .

Table 24.

Association Rules

\begin{tabular}{|c|c|}
\hline Rule Model & Results \\
\hline if $\mathrm{Q} 2=2$ then & Auditory \\
\hline if $\mathrm{Q} 2=3$ and $\mathrm{Q} 8=2$ then & Auditory \\
\hline if $\mathrm{Q} 2=3$ and $\mathrm{Q} 8=3$ and $\mathrm{Q} 7=2$ then & Auditory \\
\hline if $\mathrm{Q} 2=3$ and $\mathrm{Q} 8=3$ and $\mathrm{Q} 7=3$ then & Visual \\
\hline if $\mathrm{Q} 2=3$ and $\mathrm{Q} 8=3$ and $\mathrm{Q} 7=4$ then & Auditory \\
\hline if $\mathrm{Q} 2=3$ and $\mathrm{Q} 8=3$ and $\mathrm{Q} 7=5$ then & Auditory \\
\hline if $\mathrm{Q} 2=3$ and $\mathrm{Q} 8=4$ and $\mathrm{Q} 7=2$ then & Visual \\
\hline if $\mathrm{Q} 2=3$ and $\mathrm{Q} 8=4$ and $\mathrm{Q} 7=3$ then & Visual \\
\hline if $\mathrm{Q} 2=3$ and $\mathrm{Q} 8=4$ and $\mathrm{Q} 7=4$ then & Visual \\
\hline if $\mathrm{Q} 2=3$ and $\mathrm{Q} 8=4$ and $\mathrm{Q} 7=5$ then & Auditory \\
\hline if $\mathrm{Q} 2=3$ and $\mathrm{Q} 8=5$ then & Visual \\
\hline if $\mathrm{Q} 2=4$ and $\mathrm{Q} 5=2$ and $\mathrm{Q} 8=2$ then & Kinesthetic \\
\hline if $\mathrm{Q} 2=4$ and $\mathrm{Q} 5=2$ and $\mathrm{Q} 8=3$ then & Kinesthetic \\
\hline if $\mathrm{Q} 2=4$ and $\mathrm{Q} 5=2$ and $\mathrm{Q} 8=5$ then & Visual \\
\hline if $\mathrm{Q} 2=4$ and $\mathrm{Q} 5=3$ and $\mathrm{Q} 4=3$ then & Kinesthetic \\
\hline if $\mathrm{Q} 2=4$ and $\mathrm{Q} 5=3$ and $\mathrm{Q} 4=4$ and $\mathrm{Q} 1=3$ then & Kinesthetic \\
\hline if $\mathrm{Q} 2=4$ and $\mathrm{Q} 5=3$ and $\mathrm{Q} 4=4$ and $\mathrm{Q} 1=4$ and $\mathrm{Q} 8=3$ then & Kinesthetic \\
\hline if $\mathrm{Q} 2=4$ and $\mathrm{Q} 5=3$ and $\mathrm{Q} 4=4$ and $\mathrm{Q} 1=4$ and $\mathrm{Q} 8=4$ then & Visual \\
\hline if $\mathrm{Q} 2=4$ and $\mathrm{Q} 5=3$ and $\mathrm{Q} 4=4$ and $\mathrm{Q} 1=5$ then & Visual \\
\hline if $\mathrm{Q} 2=4$ and $\mathrm{Q} 5=3$ and $\mathrm{Q} 4=5$ then & Visual \\
\hline if $\mathrm{Q} 2=4$ and $\mathrm{Q} 5=4$ and $\mathrm{Q} 8=2$ then & Auditory \\
\hline if $\mathrm{Q} 2=4$ and $\mathrm{Q} 5=4$ and $\mathrm{Q} 8=3$ then & Visual \\
\hline if $\mathrm{Q} 2=4$ and $\mathrm{Q} 5=4$ and $\mathrm{Q} 8=4$ and $\mathrm{Q} 9=3$ then & Auditory \\
\hline
\end{tabular}




\begin{tabular}{|c|c|}
\hline Rule Model & Results \\
\hline if $\mathrm{Q} 2=4$ and $\mathrm{Q} 5=4$ and $\mathrm{Q} 8=4$ and $\mathrm{Q} 9=4$ and $\mathrm{Q} 1=3$ then & Auditory \\
\hline if $\mathrm{Q} 2=4$ and $\mathrm{Q} 5=4$ and $\mathrm{Q} 8=4$ and $\mathrm{Q} 9=4$ and $\mathrm{Q} 1=4$ then & Visual \\
\hline if $\mathrm{Q} 2=4$ and $\mathrm{Q} 5=4$ and $\mathrm{Q} 8=4$ and $\mathrm{Q} 9=4$ and $\mathrm{Q} 1=5$ then & Visual \\
\hline if $\mathrm{Q} 2=4$ and $\mathrm{Q} 5=4$ and $\mathrm{Q} 8=4$ and $\mathrm{Q} 9=5$ then & Kinesthetic \\
\hline if $\mathrm{Q} 2=4$ and $\mathrm{Q} 5=4$ and $\mathrm{Q} 8=5$ then & Visual \\
\hline if $\mathrm{Q} 2=4$ and $\mathrm{Q} 5=5$ and $\mathrm{Q} 4=3$ then & Auditory \\
\hline if $\mathrm{Q} 2=4$ and $\mathrm{Q} 5=5$ and $\mathrm{Q} 4=4$ then & Auditory \\
\hline if $\mathrm{Q} 2=4$ and $\mathrm{Q} 5=5$ and $\mathrm{Q} 4=5$ then & Visual \\
\hline if $\mathrm{Q} 2=5$ and $\mathrm{Q} 9=2$ then & Auditory \\
\hline if $\mathrm{Q} 2=5$ and $\mathrm{Q} 9=3$ and $\mathrm{Q} 1=3$ then & Kinesthetic \\
\hline if $\mathrm{Q} 2=5$ and $\mathrm{Q} 9=3$ and $\mathrm{Q} 1=4$ then & Visual \\
\hline if $\mathrm{Q} 2=5$ and $\mathrm{Q} 9=4$ and $\mathrm{Q} 3=3$ and $\mathrm{Q} 8=3$ then & Kinesthetic \\
\hline if $\mathrm{Q} 2=5$ and $\mathrm{Q} 9=4$ and $\mathrm{Q} 3=3$ and $\mathrm{Q} 8=4$ then & Visual \\
\hline if $\mathrm{Q} 2=5$ and $\mathrm{Q} 9=4$ and $\mathrm{Q} 3=3$ and $\mathrm{Q} 8=5$ then & Visual \\
\hline if $\mathrm{Q} 2=5$ and $\mathrm{Q} 9=4$ and $\mathrm{Q} 3=4$ and $\mathrm{Q} 1=3$ then & Kinesthetic \\
\hline if $\mathrm{Q} 2=5$ and $\mathrm{Q} 9=4$ and $\mathrm{Q} 3=4$ and $\mathrm{Q} 1=4$ then & Auditory \\
\hline if $\mathrm{Q} 2=5$ and $\mathrm{Q} 9=4$ and $\mathrm{Q} 3=5$ and $\mathrm{Q} 7=4$ then & Kinesthetic \\
\hline if $\mathrm{Q} 2=5$ and $\mathrm{Q} 9=4$ and $\mathrm{Q} 3=5$ and $\mathrm{Q} 7=5$ then & Auditory \\
\hline if $\mathrm{Q} 2=5$ and $\mathrm{Q} 9=5$ then $\mathrm{K}$ & Kinesthetic \\
\hline Correct: 176 out of 195 training examples. & \\
\hline
\end{tabular}

\section{$5 \quad$ Research Discussions}

There are three main issues that need to be discussed:

1. The sample collection

2. The perceived dimension to the data analysis in different tools

3. Utilization of research results.

\subsection{Sample collection}

As shown in Table 5 and Table 6 , the data collection also has an uneven distribution. For example, Table 5 shows that students in each year are not consistent. However, the nature of data collection is random. If there is an ongoing research in the future, the number of data sets for each year should be increased.

In addition, the distribution of samples in all schools and colleges of the university needs to be considered more. However, this research is a model of studying relevant factors and affecting learning patterns. If there is ongoing research in the future, the researchers aim would be to create a cooperation with executives and related parties at all levels. 


\subsection{Perceived dimension to data analysis in different tools}

The main purpose of using different data analysis tools is to compare the results in different dimensions. It can be seen that the overview of the analysis of the two tools is in the same direction, but the results are different in perception.

An important example is the statistical tools analyzed in an overview of all data. It shows that the majority of the respondents pay attention to the accepted level of all questions, as shown in Table 8, while k-Means and x-Means can illustrate the distribution in each cluster as shown in Figure 6, Figure 7, and Table 10. In addition, Table 12 to Table 22 and Figure 8 to Figure 13 show the significance of all the decision tree models.

The differences emphasize the direction and belief of the respondents. The two tools have proved that the respondents accepted the students model in different learning styles of academic achievement as concluded in the research results section.

\subsection{Utilization of research results}

The results of the research are divided into two dimensions: statistical results and results that are the prototype of the appropriate educational models (students model). From the statistics show that the respondents accept all three types of learning styles. While the model test results in each cluster are high level. Therefore, the researchers believe that the results of the research can be developed in the future. The researchers have plans and procedures as shown in Figure 14.

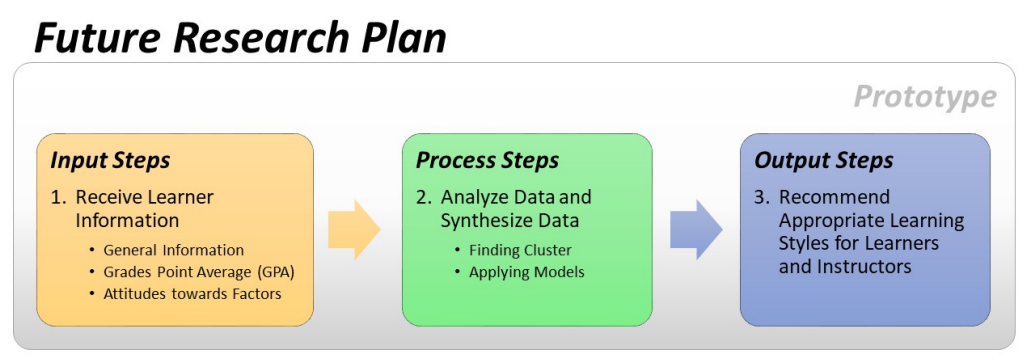

Fig. 14.Future Research

Figure 14 shows that the researchers have clear goals and steps that can be implemented in the future, which the researchers want to expand the network and scope of research to cover various universities in Thailand.

\section{Conclusion}

This research aims to answer two issues:

Question 1: How much does the academic achievement level affects the clusters and the learning style of students at the University of Phayao? 
Question 2: How much of a difference in attitude levels toward the learning style affect the clusters and the learning style of students at the University of Phayao?

The first question can be explained as shown in Table 8 that all questions in the questionnaire are accepted at the agree level, which is the average of all questions equal to 3.77. The second question can be answered in data analysis using the data mining process as shown in Table 12 to Table 22 and Figure 8 to Figure 13, which can be concluded that the number of cluster that are significant to the difference learning styles of academic achievement is 5 clusters as shown in Figure 6, Figure 7, and Table 10. Therefore, it can be concluded that this research achieved its objectives.

In future work, it will be applied with other universities in Thailand and also used in developing applications for providing a program recommended for appropriate educational programs. In addition, the researchers tried to improve the defects as discussed in the research discussion section on the next research.

\section{$7 \quad$ Acknowledgement}

This research is supported by the University of Phayao, Rajabhat Mahasarakham University, Rajamangala University of Technology Tawan-Ok, and Vongchavalitkul University in Thailand. The authors would like to thank the advisor, lecturers, students, technicians, and all respondents for their entire support.

\section{$8 \quad$ References}

[1] M. W. Apple, "Competition, Knowledge, and the Loss of Educational Vision," Philosophy of Music Education Review, vol. 11, no. 1, pp. 3-22, 2003.

[2] S. Marginson, "Higher Education in the Global Knowledge Economy," Procedia - Social and Behavioral Sciences, vol. 2, no. 5, pp. 6962-6980, Jan. 2010. https://doi.org/10.1016/j.sbspro.2010.05.049

[3] J. Overberg et al., "Internal quality management in competence-based higher education An interdisciplinary pilot study conducted in a postgraduate programme in renewable energy,” Solar Energy, vol. 177, pp. 337-346, Jan. 2019. https://doi.org/10.1016/j.solener.2018.11.009

[4] E. Kurilovas, "On data-driven decision-making for quality education," Computers in Human Behavior, Nov. 2018.

[5] P. Nuankaew and P. Temdee, "Matching of compatible different attributes for compatibility of members and groups," International Journal of Mobile Learning and Organisation, vol. 13, no. 1, p. 4, 2019. https://doi.org/10.1504/ijmlo.2019.10016604

[6] S. S. Binyamin, M. Rutter, and S. Smith, "Extending the Technology Acceptance Model to Understand Students' Use of Learning Management Systems in Saudi Higher Education," International Journal of Emerging Technologies in Learning (iJET), vol. 14, no. 03, pp. 421, Feb. 2019. https://doi.org/10.3991/ijet.v14i03.9732

[7] P. Nuankaew and P. Temdee, "Online Mentoring Model by Using Compatible Different Attributes," Wireless Pers Commun, vol. 85, no. 2, pp. 565-584, Nov. 2015. https://doi.org/10.1007/s11277-015-2755-x 
[8] P. Nuankaew, W. Nuankaew, K. Phanniphong, and S. Bussaman, "Mobile Applications for the Prediction of Learning Outcomes for Learning Strategies and Learning Achievement in Lifelong Learning," in Teaching and Learning in a Digital World, 2018, pp. 400-412. https://doi.org/10.1007/978-3-319-73204-6 45

[9] P. Nuankaew and P. Temdee, "Of online community: Identifying mentor and mentee with compatible different attributes and decision tree," in 2015 12th International Conference on Electrical Engineering/Electronics, Computer, Telecommunications and Information Technology (ECTI-CON), 2015, pp. 1-6. https://doi.org/10.1109/ecticon.2015.7207130

[10] K. Phanniphong, P. Nuankaew, D. Teeraputon, W. Nuankaew, P. Tanasirathum, and S. Bussaman, "The Distinction Learning Style in Learning Outcomes of the Secondary School Learner," in 2018 3rd Technology Innovation Management and Engineering Science International Conference (TIMES-iCON), 2018, pp. 1-5.

https://doi.org/10.1109/times-icon.2018.8621778

[11] "Thailand - National Education Act, B.E. 2542 (1999)." [Online]. Available: $\mathrm{http} / / / w w w . i l o . o r g / d y n / n a t l e x / n a t l e x 4 . d e t a i l$ ?p_lang=en\&p_isn=82860\&p_country=THA\& p_count=441. [Accessed: 20-Feb-2019].

[12] U. Ocepek, Z. Bosnić, I. Nančovska Šerbec, and J. Rugelj, "Exploring the relation between learning style models and preferred multimedia types," Computers \& Education, vol. 69, pp. 343-355, Nov. 2013. https://doi.org/10.1016/j.compedu.2013.07.029

[13] H. Alanbaei, M. H. Faisal, and A. A. Alsumait, "VAK Personalized Learner-Sourced ENotes," in 2018 International Conference on Computing Sciences and Engineering (ICCSE), 2018, pp. 1-5. https://doi.org/10.1109/iccse1.2018.8374226

[14] K. Crockett, A. Latham, and N. Whitton, "On predicting learning styles in conversational intelligent tutoring systems using fuzzy decision trees," International Journal of HumanComputer Studies, vol. 97, pp. 98-115, Jan. 2017. https://doi.org/10.1016/i.ijhcs.2016.08.005

[15] W. Nuankaew, P. Nuankaew, S. Bussaman, and P. Tanasirathum, "Hidden academic relationship between academic achievement and higher education institutions," in 2017 International Conference on Digital Arts, Media and Technology (ICDAMT), 2017, pp. 308313. https://doi.org/10.1109/icdamt.2017.7904982

[16] A. M. Shahiri, W. Husain, and N. A. Rashid, "A Review on Predicting Student's Performance Using Data Mining Techniques,” Procedia Computer Science, vol. 72, pp. 414-422, Jan. 2015. https://doi.org/10.1016/j.procs.2015.12.157

[17] S. Kaeophanuek, J. Na-Songkhla, and P. Nilsook, "A Learning Process Model to Enhance Digital Literacy using Critical Inquiry through Digital Storytelling (CIDST)," International Journal of Emerging Technologies in Learning (iJET), vol. 14, no. 03, pp. 22-37, Feb. 2019. https://doi.org/10.3991/ijet.v14i03.8326

[18] Y. Zheng, Y. Yang, H. Chai, M. Chen, and J. Zhang, "The Development and Performance Evaluation of Digital Museums Toward Second Classroom of Primary and Secondary School - Taking Zhejiang Education Technology Digital Museum as An Example," International Journal of Emerging Technologies in Learning (iJET), vol. 14, no. 02, pp. 69-84, Jan. 2019. https://doi.org/10.3991/ijet.v14i02.7897

\section{Authors}

Pratya Nuankaew received a B.Ed. Degree in Educational Technology in 2001, M.Sc. degree in Information Technology in 2008 from Naresuan University, and a Ph.D. degree in Computer Engineering in 2018 from Mae Fah Luang University. He 
is currently a lecturer at the School of Information and Communication Technology, University of Phayao, Phayao, Thailand. His research interests are in online mentoring model, mentoring relationships, social network analysis, ubiquitous computing, learning analytics, digital education, and educational data mining. (E-mail pratya.nu@up.ac.th)

Wongpanya Nuankaew received a B.Sc. degree in Computer Science in 2004, and M.Sc. degree in Information Technology in 2007 from Naresuan University. She is currently a lecturer at the Faculty of Information Technology, Rajabhat Maha Sarakham University, Maha Sarakham, Thailand. Her research interests are in digital education, innovation and knowledge management, data science, and big data and information technology management.

Kanakarn Phanniphong received his B.B.A. degree in Information System in 2005 from Rajamangala University of Technology Thanyaburi, Pathum Thani, Thailand, M.B.A. degree Business Administration in 2008 and D.B.A. degree in Business in 2018 from Pathumthani University, Pathum Thani, Thailand. He is currently a lecturer at the Faculty of Business Administration and Information Technology, Rajamangala University of Technology Tawan-Ok, Bangkok, Thailand. His research interests are data science, accounting information system, innovation and knowledge management, self-service technologies, and management information system. (E mail - kanakarn.p@cpc.ac.th)

Sasithon Imwut is a researcher at Vongchavalitkul University, Nakhon Ratchasima, Thailand. He is available on mail sasithon_imv@vu.ac.th

Sittichai Bussaman received his B.Sc. in Statistic in 1990 from Srinakharinwirot University, M.Sc. in Computer Science and Information Technology in 1997 from King Mongkut's Institute of Technology Ladkrabang and Ph.D. in Educational Technology and Communications in 2013 from Mahasarakham University. He is currently an Associate Professor at the Faculty of Science and Technology, Rajabhat Maha Sarakham University, Maha Sarakham, Thailand. His research interests are data mining in education, online learning, pattern recognition, and Artificial Intelligence. E mail - sittichai.bus@gmail.com)

Article submitted 2019-02-20. Resubmitted 2019-04-03. Final acceptance 2019-04-04. Final version published as submitted by the authors 